J. Clin. Chem. Clin. Biochem.

Vol. 24, 1986, pp. 1017-1021

(C) 1986 Walter de Gruyter \& Co.

Berlin - New York

\title{
Two-Dimensional Gel Electrophoresis, Isoelectric Focusing and Agarose Gel Electrophoresis in the Diagnosis of Multiple Sclerosis
}

\author{
By F. Wiederkehr, H. Imfeld and D. J. Vonderschmitt \\ University Hospital, Central Laboratory of Clinical Chemistry, Zürich, Switzerland
}

(Received April 21/August 15, 1986)

\begin{abstract}
Summary: Two dimensional gel electrophoresis (2-DE), isoelectric focusing (IEF) and agarose gel electrophoresis (AGE) were used to examine cerebrospinal fluid (CSF) and sera from 22 patients with confirmed multiple sclerosis, 11 patients with probable multiple sclerosis and 20 control patients with non-inflammatory neurological diseases of the central nervous system (CNS). All of the 22 patients with confirmed multiple sclerosis showed abnormal patterns of oligoclonal IgG in all three methods. In the CSF from patients with probable multiple sclerosis, oligoclonal IgG was detectable in 18 percent with AGE, in 72 percent with IEF and 90 percent with 2-DE. No oligoclonal IgG was observed in subjects with non-inflammatory neurological diseases. Many artefacts in IEF, which lead to misinterpretation, are eliminated in the 2-DE system. Based on our observations and this study in particular, it is evident that some patients have IgG changes which can be detected only by 2-DE. The application of research-oriented 2-DE for routine clinical purposes is still limited by its cost and technical complexity.
\end{abstract}

Zweidimensionale Gelelektrophorese, isoelektrische Fokussierung und Agarose-Gelelektrophorese als Hilfsmittel für die Diagnose der multiplen Sklerose

Zusammenfassung: Mit Hilfe der zweidimensionalen Gelelektrophorese (2-DE), isoelektrischen Fokussierung (IEF) und Agarose-Gelelektrophorese (AGE) wurden Liquorproben und Seren von 22 Patienten mit gesicherter multipler Sklerose, 11 Patienten mit fraglicher multipler Sklerose und 20 Kontrollpatienten mit nichtentzündlichen neurologischen Erkrankungen untersucht. Bei allen 22 Patienten mit gesicherter Diagnose einer multiplen Sklerose ließen sich mit allen drei elektrophoretischen Techniken oligoklonale IgG nachweisen. Im Liquor von Patienten mit fraglicher multipler Sklerose ließen sich in $18 \%$ mittels AGE und in $72 \%$ der Fälle mittels IEF oligoklonale IgG nachweisen. Hingegen gelang es mittels $2-\mathrm{DE}$, in $90 \%$ der fraglichen Fälle oligoklönale IgG nachzuweisen. Bei den nichtentzündlichen neurologischen Krankheiten wurden keine oligoklonalen IgG gefunden. Viele Artefakte, die bei der IEF auftreten können, werden mit dem 2-DE System eliminiert. Aufgrund der vorliegenden Ergebnisse ist es offensichtlich, daß bei einigen Patienten nur mittels 2-DE oligoklonale IgG nachgewiesen werden können. Der Einsatz der forschungsorientierten 2-DE für Routineuntersuchungen ist gegenwärtig noch begrenzt durch ihre hohen Kosten und technischen Schwierigkeiten.

\section{Introduction}

Examination of cerebrospinal fluid (CSF) is of potential value in searching for changes in neurological diseases, owing to its clinical availability and its close association with nervous tissue. Above all, the detection of immunoglobulin $\mathrm{G}(\mathrm{IgG})$ of restricted hetero- geneity in CSF is an important aid for the diagnosis of multiple sclerosis, especially in early cases, but also of other inflammatory diseases of the central nervous system (CNS). For demonstration of these so-called oligoclonal IgG, agarose gel electrophoresis (AGE) is at present the most common procedure $(1,2)$. 
However, one or more non-IgG bands appear sometimes in the region where oligoclonal IgG bands migrate, and this makes the evaluation of the AGEpattern difficult (3). Isoelectric focusing (IEF) on polyacrylamide gel resolves many proteins better than AGE, including oligoclonal IgG's. Sometimes, 30 or more oligoclonal bands can be demonstrated at the cathodic side by this method. IEF has been said to be diagnostically superior to AGE (4), but even normal CSF and serum samples show several bands at the cathodic side on IEF if large amounts of IgG are applied (5). This makes it difficult to distinguish between normal and pathologic protein patterns.

In contrast to AGE and IEF, two-dimensional electrophoresis (2-DE) on polyacrylamide gels (6) separates the immunoglobulins into light and heavy chains, because the first dimension is run under dissociating conditions. CSF from patients with inflammatory diseases of the CNS show an oligoclonal zone in the region of the Ig light chains on the 2-DE pattern (7$9,19)$. The novel immunoglobulins appear as sharply edged spots because of their limited heterogeneity.

In the following study we used AGE, IEF and 2$\mathrm{DE}$ to evaluate CSF specimens from patients with clinically definite multiple sclerosis, with probable multiple sclerosis and a control population of 20 with other neurological diseases.

\section{Materials and Methods}

\section{Patients}

The CSF samples were collected by lumbar puncture from patients treated at the Department of Neurology, University Hospital, Zürich. The patients included 22 clinically definite multiple sclerosis cases, 11 cases with probable multiple sclerosis, and 20 controls with other neurologic diseases. Cell counts were done by the standard technique of the hospital laboratory. At the time of CSF examination by AGE, IEF and 2-DE, none of the patients had received any drug therapy that could influence the protein pattern.

\section{Procedure}

The samples were stored at $-20^{\circ} \mathrm{C}$ without preservatives. The CSF were concentrated $10-20$ fold by air pressure ultrafiltration (Sartorius $\mathrm{GmbH}$, Göttingen, F. R. G.) to a protein content of 3-6 g/l. The total protein concentration was measured by the Coomassie Blue Bradford Assay (Bio-Rad), as described by Tracy (10).

\section{Agarose gel electrophoresis}

For AGE we used commercial plates (Ready-System, Zurzach, Switzerland). After electrophoresis, the agarose slides were stained with Ponceau red.

\section{Polyacrylamide isoelectric focusing}

Thin layer IEF was carried out on a 2117 Multiphor (LKB). The gel size was $12.5 \times 13.0 \mathrm{~cm}$ with a thickness of $1 \mathrm{~mm}$. They consisted of $40 \mathrm{~g} / \mathrm{l}$ acrylamide and $20 \mathrm{~g} / 1 \mathrm{l} .5-10$ ampholytes (Ampholines, LKB). The anolyte was $1 \mathrm{~mol} / 1$ phosphoric acid, the catholyte was $1 \mathrm{~mol} / \mathrm{l}$ sodium hydroxide. Fifteen microlitres of CSF sample was pipetted onto the Whatman paper wick (10 $\times 0.5 \mathrm{~mm}$ ). Separation was carried out at 800 volts for 4 hours at $2{ }^{\circ} \mathrm{C}$.

\section{Two dimensional polyacrylamide gel electrophoresis}

2-DE was performed as described (9). For first dimension IEF we used capillary gel colums $(14 \mathrm{~cm} \times 0.15 \mathrm{~cm}$ i.d.) with a 4: 1 mixture of carrier ampholytes, $\mathrm{pH}$ ranges $3.5-10$ and 57. The anolyte was $40 \mathrm{mmol} / \mathrm{l}$ phosphoric acid, and the catholyte was $100 \mathrm{mmol} / \mathrm{l}$ sodium hydroxide. The separation was done at $9000 \mathrm{~V} \times \mathrm{h}$. the second dimension was run in uniform $10 \%$ acrylamide gels, $1.5 \mathrm{~mm}$ thick.

\section{Silver stain}

The IEF-gels and the 2-DE gels were silver stained according to Oakley et al. (11) with some modifications (9). After the rinse in silver diammine solution and water, each gel was immersed individually for 20 seconds in a $200 \mathrm{mg} / \mathrm{l}$ solution of sodium thiosulphite. For photography we used a Polaroid CU5 Closeup Land Camera System and Polaroid Land Film Type 665. The IEF patterns and the 2-DE patterns were evaluated by visual inspection.

\section{Results}

Figure 1 shows a typical IEF IgG pattern and a 2DE IgG pattern from a normal CSF. Usually, we concentrated CSF 10-20 fold to detect more easily the oligoclonal IgG. A comparison of the 2-DE patterns of concentrated and unconcentrated CSF revealed no qualitative differences. The polyclonal IgGs in IEF migrate over a wide $\mathrm{pH}$ range and they form a diffuse background without any sharp band (fig. $1 \mathrm{~b})$. In contrast to IEF and AGE, 2-DE separates the IgG into heavy and light chains (fig. $1 \mathrm{a}$ ). The IgG heavy chains at molecular weight 55000 are largely unresolved, whereas the polyclonal IgG light chains at molecular weight 23000 are separated in six subfractions as previously described (19). Discrete spots appear above the IgG light chain sub-fractions (figs. $1-3$ ). They are not removable by Staphylococcus Protein $\mathrm{A}$ and do not react with anti-kappa and anti-lambda antibodies (19). These proteins; except one (no. 6), which is limited to CSF, are also found in the corresponding serum. The serum proteins nos. $3-5$ and 7 are always detectable in CSF, whereas the two serum proteins nos. 1, 2 are only sometimes found in CSF. Serum protein no. 8 is detectable in CSF depending on $\mathrm{pH}$ gradient stabilization in the alkaline region. It is important to know the positions of these eight spots, in order to distinguish them from oligoclonal immunoglobulins. The identification of 


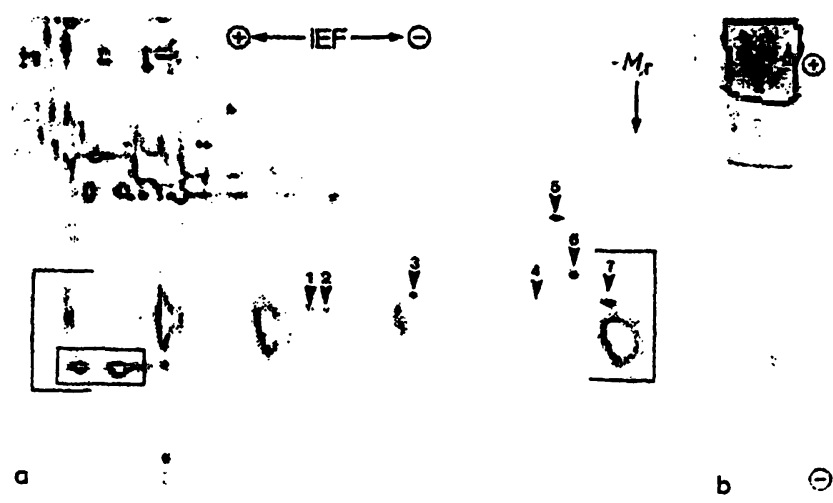

Fig. 1. a) 2-DE pattern of the $\mathrm{IgG}$ light chain region from a normal CSF. The non-IgG proteins are numbered from $1-7$; Nos. $1-4,7$ are unknown proteins derived from serum, No. 5 represents the $\mathrm{C} 4 \gamma$-chain, No. 6 is a CSF-specific protein not found in serum. Apolipoprotein A-I is enframed.

b) The corresponding IEF pallern. The polyclonal IgGs form a diffuse background without any sharp bands.

apolipoprotein A-1 and C4 $\gamma$-chain is facilitated by comparison with other 2-DE patterns of human plasma and serum proteins $(10,20)$.

We investigated 22 CSF specimens from patients with clinically definite multiple sclerosis, 11 with probable multiple sclerosis and 20 control patients with no immunologic activity in the CNS, as shown in table 1. The control group included patients with diagnosis such as epilepsy, migraine, schizophrenia, and transient ischaemic attacks. CSF protein concentration values were obtained in all cases. The mean values from patients with clinically definite multiple sclerosis were normal or slightly elevated. The CSF IgG index according to Tibbelnig et al. (12) was elevated in all 22 cases (greater than 0.7 in our laboratory), in parallel with an increased CSF-IgG. With each CSF sample of multiple sclerosis patients we carried out an AGE, a 2-DE and an IEF. Invariably we found oligoclonal bands, or oligoclonal zones.

Tab. 1. Agarose gel electrophoresis (AGE), isoelectric focusing (IEF) and two-dimensional gel electrophoresis (2-DE) results obtained from $53 \mathrm{CSF}$ samples.

\begin{tabular}{llll}
\hline $\begin{array}{l}\text { Diagnostic group } \\
\text { (no. of patients) }\end{array}$ & $\begin{array}{l}\text { AGE with } \\
\text { oligoclonal } \\
\text { bands }\end{array}$ & $\begin{array}{l}\text { IEF with } \\
\text { oligoclonal } \\
\text { bands }\end{array}$ & $\begin{array}{l}\text { 2-DE with } \\
\text { oligoclonal } \\
\text { zones }\end{array}$ \\
\hline $\begin{array}{l}\text { Clincally definite } \\
\text { multiple sclerosis (22) }\end{array}$ & 22 & 22 & 22 \\
$\begin{array}{l}\text { Probable multiple } \\
\text { sclerosis (11) }\end{array}$ & 2 & 8 & 10 \\
$\begin{array}{l}\text { Control group with } \\
\text { noninflammatory di- } \\
\text { seases of the CNS (20) }\end{array}$ & 0 & 0 & 0 \\
\hline
\end{tabular}

Figure 2 represents the IEF and the 2-DE pattern from a CSF of a multiple sclerosis patient. The newly appearing polypeptides in the oligoclonal zone on the 2-DE gel were identified as immunoglobulin light chains by electroblotting to nitrocellulose paper and staining with anti-kappa and anti-lambda antibodies coupled to peroxidase. The corresponding sera were normal. The polyclonal light chain background in CSF was in all cases strongly expressed. Each patient's oligoclonal pattern was unique and did not change over the course of a patient's disease (9). We did not find a specific oligoclonal zone (i.e. number of oligoclonal $\operatorname{lgG}$ ), which correlated to duration or degree of disability.

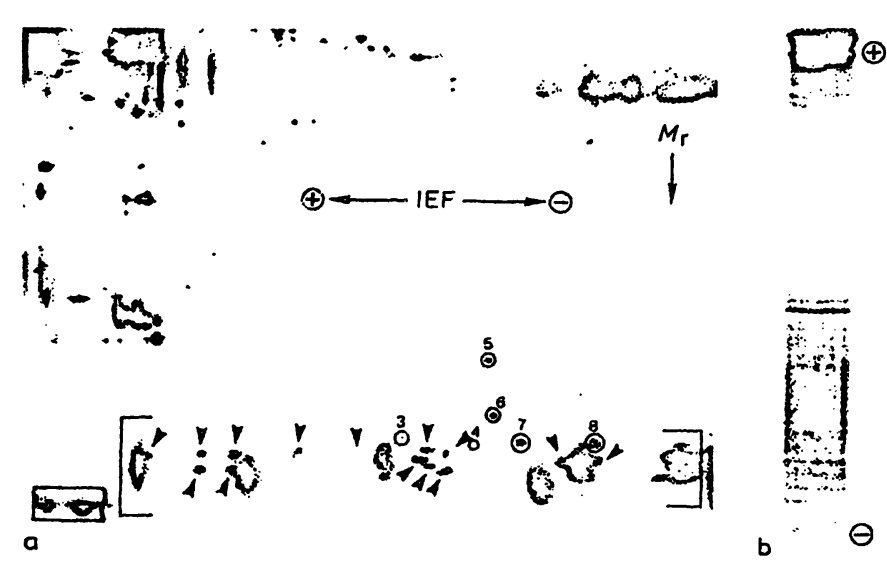

Fig. 2. a) Oligoclonal zone in the $\operatorname{IgG}$ light chain region of CSF from a 28-year-old woman with multiple sclerosis. The sample was taken during an exacerbation 1 year after the onset of the disease (total protein in CSF $530 \mathrm{mg} / \mathrm{l} ; \mathrm{IgG} 98 \mathrm{mg} / \mathrm{l} ; \mathrm{IgG}$ index 1.8). The novel IgG light chain proteins are indicated by arrows, apolipoprotein A-I is enframed. The non$\mathrm{IgG}$ proteins are numbered from $1-8$ as described in figure $1 \mathrm{a}$; No. 8 (not mentioned in fig. 1) also represents an unknown protein fraction derived from serum.

b) The corresponding IEF pattern shows oligoclonal bands in the $\gamma$-globulin region.

Of great interest are the CSF from patients with probable multiple sclerosis. They were analysed by AGE, IEF and 2-DE. In two cases only, we found an elevated CSF $\gamma$-globulin on AGE and an analogous increased $\mathrm{IgG}$ index. Of significance is a comparison between IEF and 2-DE. Eight out of eleven probable multiple sclerosis cases displayed oligoclonal bands by IEF, however, in two cases, the bands appeared quite faint. All IEF gels were stained by silver diammine. Immunoperoxidase staining, which highlighted the IgG bands, was omitted. In contrast to IEF, 10 out of 11 patients showed a clear oligoclonal zone on the 2-DE gel, which points to an immunoreaction in the CNS. One case with an oligoclonal zone on the 2-DE gel, but no oligoclonal bands in the corresponding IEF gel, is demonstrated in figure 3. 


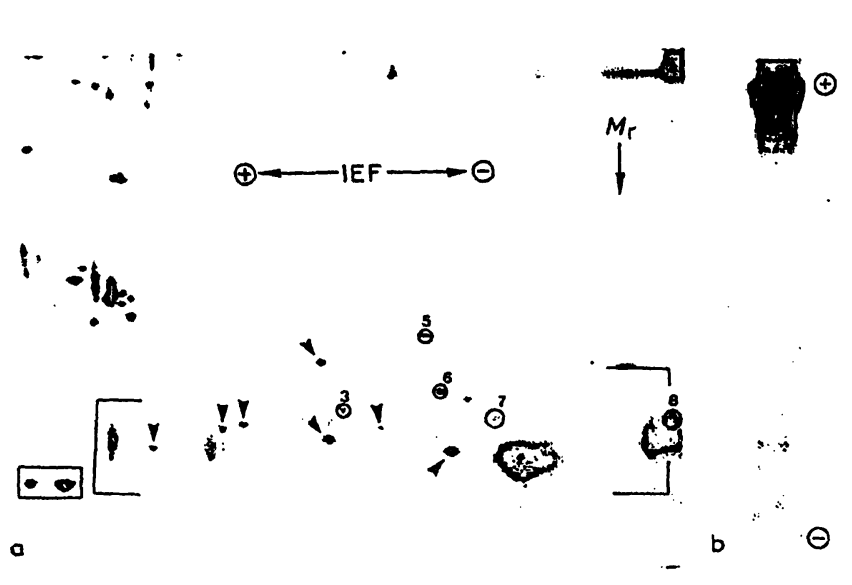

Fig. 3. a) Oligoclonal zone in the IgG light chain region of CSF from a 32-year-old man with an early probable multiple sclerosis (total protein in CSF $400 \mathrm{mg} / \mathrm{l}$; IgG $38 \mathrm{mg} / \mathrm{l} ; \mathrm{IgG}$ index 1.5). The novel IgG light chain proteins are indicated by arrows, apolipoprotein A-I is enframed. The non-IgG proteins are numbered from $1-8$ as described in figure $2 a$.

b) The corresponding IEF pattern shows no sharp band in the $\gamma$-globulin region.

In one CSF from a patient with a probable multiple sclerosis we were not able to detect oligoclonal Ig with any of the three electrophoretic techniques.

\section{Discussion}

The main reason in neurology for analysing CSF and the corresponding serum with an electrophoretic technique is to detect any oligoclonal IgG that are not found in serum or "normal" CSF. The detection of oligoclonal IgG is important in the diagnosis of multiple sclerosis, especially in early or a non-typical cases. A simple and reproducible technique is AGE, which is often sufficient for identifying CSF oligoclonal bands. In all cases with clinically defined multiple sclerosis we were able to find a clear sub-banding in the increased CSF $\gamma$-globulin fraction on the agarose gel, and in parallel on oligoclonal zone on the 2-DE gel.

It is of great interest to compare the results from 2DE and IEF. IEF has a much higher resolution capacity than AGE. This makes it useful for research work, but difficult to use in routine diagnostic work, as it may be difficult to distinguish between normal and pathologic protein patterns (13). Both Laurenzi \& Link (14) and Hershey \& Trotter (15) compared AGE and IEF, and they found a higher rate of false positive results in IEF. One problem concerns the silverstained IEF gels. As described by Wurster (16), artefactual silver staining can occur in the form of con- tinuous bands especially around $\mathrm{pH} 8$. It has been suggested that the bands probably represent stained species of ampholytes which have not been removed from the gel despite extensive washing. In 2-DE gels, however, the ampholytes were separated from the IgG-fractions, and artefactual staining is eliminated. Another cause for misinterpretation of the IEF pattern is the CSF-specific $\gamma$-trace protein. It usually has a very cathodal position in the IEF gel at $\mathrm{pH} 9.3$, but can, for various reasons (i.e. storage of CSF), shift position to $\mathrm{pH} 8.0$, where it may be misinterpreted as an IgG fraction (17). On the 2-DE gel, it is one of the CSF-specific protein group with a definite position (9), probably at molecular weight $35000-$ 38000 . It does not disturb the interpretation of the IgG light chain pattern at molecular weight 22000 23000 . In contrast to the first dimension of 2-DE gels, the routinely used IEF gels are run at low ionic strength. This could lead to oligomeric forms of IgG which may derive from artefactual aggregation (18). In contrast to agarose electrophoresis and 2-DE, the IEF method is less suitable for identification of IgM. Patients with neurosyphilis displayed a distinct IgM heavy chain fraction above albumin in 2-DE, while IEF of CSF yielded only two faint bands that are difficult to interpret. It may be assumed that the demonstration of IgA and IgM on IEF of CSF involves greater difficulties compared with 2-DE.

In two cases with presumptive multiple sclerosis, only the 2-DE system showed positive findings. Similar results have been described by Harrington et al. (7), who detected oligoclonal IgG in two patients with clinical features of multiple sclerosis with 2-DE, but not with IEF. Perhaps the IgG were too basic for IEF gels; the IgG would then migrate into the cathode wick and had be removed from the gel. In the 2-DË system, the IgG light chains are separated from the heavy chains. The light chains in the isolated state probably have less basic properties and are well separated in the first dimension.

Our results show that the diagnostic value of 2-DE is better than that of AGE and IEF. Many artefacts occurring in IEF, which can lead to misinterpretation, are eliminated in the 2-DE system. Especially in limiting cases with very faint oligoclonal bands on the IEF gel, the results from 2-DE are more unequivocal. Also in blood-contaminated CSF-samples, oligoclonal IgG are much better detectable by 2-DE than by IEF. On the other hand, 2-DE is of great research value and its application to routine clinical analysis is still limited by the expense and the technical difficulty. 


\section{References}

1. Link, H. (1973) Clin. Chim. Acta 46, 383-389.

2. Johnson, K. P., Arrigo, S. C., Nelson, B. J. \& Ginsberg, A. (1977) Neurology 27, 273-277.

3. Link, H. \& Kostulas, V. (1983) Clin. Chem. 29, 810-815.

4. Delmotte, P. \& Gonsette, G. (1977) J. Neurol. 215, $27-$ 37.

5. Nilsson, K. \& Olsson, J. E. (1978) Clin. Chem. 24, 11341139.

6. O'Farrell, P. H. (1975) J. Biol. Chem. 250, 4007-4021.

7. Harrington, M. G., Merril, C. R., Goldman, G., Xu, X. H. \& Mc Farlin, D. E. (1984) Electrophoresis 4, 236-245.

8. Walsh, J. M., Tourtellotte, W. W., Roman, J. \& Dreyer, W. (1985) Clin. Immunol. Immunopathol. 35, 313-327.

9. Wiederkehr, F., Ogilvie, A. \& Vonderschmitt, D. J. (1985) Clin. Chem. 31, 1537-1542.

10. Tracy, R. P., Currie, R. M. \& Young, D. S. (1982) Clin. Chem. 28, 890-899.

11. Oakley, B. R., Kirsch, D. R. \& Morris, N. R. (1980) Anal. Biochem. 105, $361-363$.
12. Tibbling, G., Link, H. \& Ohman, S. (1977) Scand. J. Clin. Lab. Invest. 37, 385-390.

13. Nilsson, K. \& Olsson, J. E. (1978) Clin. Chem. 24, 11341139.

14. Laurenzi, M. A. \& Link, H. (1978) Acta Neurol. Scand. $58,141-147$.

15. Hershey, L. A. \& Trotter, J. L. (1980) Ann. Neurol. 8, $426-434$.

16. Wurster, U. (1983) Electrophoresis '82, W. de Gruyter, Berlin, New York, pp. 249-259.

17. Olsson, J. E. \& Nilsson, K. (1979) Neurology 29, 13831391.

18. Chrambach, A., An der Lan, B., Mohrmann, H. \& Felgenhauer, H. (1981) Electrophoresis 2, 279-287.

19. Wiederkehr, F., Ogilvie, A. \& Vonderschmitt, D. J. (1986) Electrophoresis 7, 89-95.

20. Anderson, N. L. \& Anderson, N. G. (1977) Proc. Natl. Acad. Sci. USA 74, 5421-5425.

Dr. F. Wiederkehr

Med.-Chem. Zentrallabor

Universitäts-Spital Zürich

Rämistr. 100

CH-8091 Zürich 
